\title{
Depression and Anxiety
}

CASE SERIES

\section{Trauma Precursors of Obsessive Compulsive Disorder - A Case Series}

\author{
Vyjayanthi Subramanian $^{1}$ and Prashanth Mayur ${ }^{2,3^{*}}$
}

${ }^{1}$ Associate Professor Psychiatry, MS Ramaiah Medical College, Bengaluru, India

${ }^{2}$ Senior Staff Specialist in Psychiatry, Mood Disorders Unit, Cumberland Hospital, Westmead, Sydney, Australia

${ }^{3}$ Clinical Senior Lecturer, Department of Psychological Medicine, University of Sydney, Sydney, Australia

*Corresponding author: Dr. Prashanth Mayur FRANZCP, PhD, Senior Staff Specialist in Psychiatry, Mood Disorders Unit, Cumberland Hospital, Westmead, Sydney; Clinical Senior Lecturer, Department of Psychological Medicine, University of Sydney, Sydney, Australia

\begin{abstract}
Introduction: Traumatic events are a precursor for not only post traumatic stress disorder but also obsessive compulsive disorder, which tend to have a generally better outcome and response to interventions. Such cases have not been described from an Indian sub-continental background.

Methods: This case series of 19 patients were collected by a single clinician at a Trauma Focused Outpatient Clinic over a number of years through semi-structured clinical assessments and structured evaluation of traumatic events (Life Events Check List) and severity of obsessive compulsive disorders (Yale Brown obsessive compulsive scale) followed by interventions.
\end{abstract}

Discussion: During assessment there was a common occurrence of past traumatic events following the initial presentation with predominantly obsessive compulsive symptoms in a diverse population representative of the Indian sub-continental background. Death due to a sudden unnatural cause was the most common traumatic events representing this case series. The vignettes illustrate a clinical need to explore traumatic events that may not be revealed at the outset of the assessment.

Conclusion: The case series provides clinical illustration to the construct of delayed type of post traumatic obsessive compulsive disorder in a predominantly non-western population. exploring trauma that occurred months earlier to the presentation of OCD may provide an aetiological substrate to the occurrence of OCD and may inform clinical approaches that are broader than conventional medication treatments for OCD.

\section{Introduction}

Post traumatic stress disorder (PTSD) and obsessive compulsive disorder (OCD) are classified as separate categories under the broad rubric of Anxiety disorders in ICD-10 [1]. Phenomenologically, PTSD shares features that are similar to or even identical with OCD [2]. The autonomic hyper-arousal or flash backs of post traumatic stress disorders to reminders of aspects of trauma may resemble obsessive fears to an onlooker who has no knowledge of the trauma hence may not identify the traumatic reminders. Intrusive memories of trauma also resemble the intrusions of OCD and there is significant avoidance of reminders of trauma similar to OCD. Many compulsive rituals may occur in PTSD that is self protective as perceived by the patient but they are irrational when viewed objectively because they are occurring to a threat that has already occurred and may not exist in the present. Epidemiologically OCD is ten times more common among victims of PTSD [2]. Even though classificatory systems in psychiatry continue to remain atheoretical, the question of traumatic events being aetiologically connected to $O C D$ is a clinically relevant one since its course and outcome may entirely different to OCD arising without a traumatic antecedent [3-6]. OCD developing after a traumatic event may be an etiologically distinct subtype of OCD with different genetic and neuro-cognitive characteristics or different treatment outcomes [3,4]. Literature on post traumatic OCD is mainly limited to a western cohort of patients. However 
there is recent evidence to suggest that the aetiological substrate for OCD may differ between non-western and western (Caucasian) populations with trauma being the dominant precursor in the non-western population as opposed to substance abuse in the western (Caucasian) population [7]. Medication use to treat OCD was more prevalent in the western population in the cross cultural study by Medeiros and others [7]. The following case-series from a non-western population are presented to substantiate this phenomenon.

\section{Methods}

All these cases were collected over a period of 10 years between 2006 and 2016. All were assessed in one or more sessions of clinical interviews as a part of a comprehensive clinical assessment and management by the author (VS) in a Psychological Trauma focused clinic at a tertiary referral general metropolitan hospital in Bengaluru India. Informed Voluntary Consent was collected from each of these patients. The vignettes have been de-identified to maintain confidentiality. The vignettes were extracted from file notes maintained by VS. during her assessments and follow-ups with the patients. In each of the vignettes the onset of the OCD symptoms were approximately delayed by 6 months following the onset of the traumatic event and at least 6 months after the commencement of traumatic events in cases of domestic violence or ongoing abuse. These are self-reported by the patients and also were independently verified from collateral sources particularly through family members who accompanied the patients as is the cultural norm in India. Table 1 contains the Yale Brown Obsessive Compulsive Score-severity [8] and Life Events Scale [9] for each of the individual patients. All the patients in the case series below were diagnosed with OCD as per ICD-10 classification. There is a brief description of management strategies that were used for each of the patients.

\section{Cases}

\section{Case 1 (Witnessing an accidental death of a child)}

A middle aged married lady Mrs. A with two children

Table 1: Life Events and YBOCS score (Yale Brown Obsessive Compulsive Scale).

\begin{tabular}{|c|c|c|}
\hline & Life Event (Check List) & YBOCS Score \\
\hline $\begin{array}{l}\text { Case 1- Causing the death of someone accidentally/ } \\
\text { intentionally }\end{array}$ & $\begin{array}{l}\text { Transportation accident (for example, car accident, boat } \\
\text { accident, train wreck, plane crash) } \\
\text { Serious injury, harm, or death you caused to someone } \\
\text { else }\end{array}$ & 32 \\
\hline Case 2- Sudden death of father & Sudden, unexpected death of someone close to you & 30 \\
\hline Case 3- Life threatening event a macabre dare & $\begin{array}{l}\text { Life-threatening illness or injury } \\
\text { Severe human suffering } \\
\text { (Humiliation by peer group/bullying) }\end{array}$ & 38 \\
\hline $\begin{array}{l}\text { Case 4- Domestic violence } \\
\text { Sudden death of mother- CA breast } \\
\text { Sudden death of sister- Ovarian Cancer }\end{array}$ & $\begin{array}{l}\text { Physical assault (for example, being attacked, hit, } \\
\text { slapped, kicked, beaten up). } \\
\text { Sudden, unexpected death of someone close to you }\end{array}$ & 32 \\
\hline Case 5- Sudden death of adoptive father & Sudden unexpected death of someone close to you & 40 \\
\hline $\begin{array}{l}\text { Case 6- Consumption of overdose of Zolpidem } \\
\text { unintentional }\end{array}$ & $\begin{array}{l}\text { Exposure to toxic substance (for example, dangerous } \\
\text { chemicals, radiation) }\end{array}$ & 35 \\
\hline Case 7- Dog bite & $\begin{array}{l}\text { Physical assault (for example, being attacked, hit, } \\
\text { slapped, kicked, beaten up) } \\
\text { Life threatening illness or injury }\end{array}$ & 40 \\
\hline $\begin{array}{l}\text { Case 8- Dowry harassment and physical abuse by } \\
\text { in laws }\end{array}$ & $\begin{array}{l}\text { Physical assault (for example, being attacked, hit, } \\
\text { slapped kicked, beaten up) }\end{array}$ & 39 \\
\hline Case 9- Sexual harassment at workplace & Other unwanted or uncomfortable sexual experience & 40 \\
\hline Case 10- Diagnosis of Bipolar affective disorder & Life threatening illness or injury & 29 \\
\hline Case 11- Accidental death of husband witnessed & Sudden, unexpected death of someone close to you & 36 \\
\hline Case 12- Death of son by murder & $\begin{array}{l}\text { Sudden, violent death (for example, homicide; suicide) } \\
\text { Sudden unexpected death of someone close to you }\end{array}$ & 30 \\
\hline $\begin{array}{l}\text { Case13- Father diagnosed with motor neuron } \\
\text { disease on ventilator + death of grandmother by } \\
\text { hepatic carcinoma }\end{array}$ & $\begin{array}{l}\text { Severe human suffering } \\
\text { Sudden unexpected death of someone close to you }\end{array}$ & 40 \\
\hline $\begin{array}{l}\text { Case 14- Physical investigation without informed } \\
\text { consent under threat of life threatening illness } \\
\text { suspected by hematuria }\end{array}$ & Life threatening illness or injury & 39 \\
\hline $\begin{array}{l}\text { Case 15- Multiple surgeries for life threatening } \\
\text { illnesses }\end{array}$ & Life threatening illness or injury & 40 \\
\hline $\begin{array}{l}\text { Case } 16-\text { Narration of past romantic relationship by } \\
\text { fiance' }\end{array}$ & Any other stressful event or experience & 39 \\
\hline $\begin{array}{l}\text { Case17- Sexual contact with a transgender while } \\
\text { intoxicated and coercion }\end{array}$ & $\begin{array}{l}\text { Sexual assault (rape, attempted rape, made to perform } \\
\text { any type of sexual act through force or threat of harm) }\end{array}$ & 40 \\
\hline $\begin{array}{l}\text { Case 18- Death of father by hepatic carcinoma } \\
\text { Death of mother by violent accident }\end{array}$ & Sudden unexpected death of someone close to you & 40 \\
\hline Case 19- Death of husband by suicide & Sudden unexpected death of someone close to you & 35 \\
\hline
\end{tabular}


presented with irrational fears of harm or accidents happening to her children and compulsive telephoning of the school, the van drivers every day within minutes of the last bell of the school. She also experienced similar fears towards her elderly parents. On further questioning patient revealed that about 6 months ago her husband who was driving the car and herself were travelling in their car on a highway when suddenly a child came in front of their car and was killed on spot since her husband was unable to apply the brakes instantly. There was a litigation suit that they were facing in the court. Mrs. A experienced intrusive thoughts of being hung to death and her children meeting with the similar accident and dying. These symptoms were intrusive and ego dystonic. In the following sessions Mrs. A showed a gradual improvement in symptoms with Fluvoxamine integrated with trauma focused psychotherapy.

\section{Case 2 (Sudden unexpected death of father)}

Mr. B aged 28 years presented with repeated fears of death due to cardiac arrest and was compulsively undergoing ECG echocardiography and other investigations. These fears were intrusive and ego dystonic as perceived by him. The fears were not overvalued ideas that he may have a cardiac ailment. On further enquiry patient revealed that his father who was undiagnosed case of hypertension had died of massive cardiac arrest 6 months ago and the sudden grief was traumatic to the patient. Patient also had another significant life event; he had a divorce and had to fight a law suit, forced to pay a compensation of a large sum of money to procure the divorce, this happened soon after his father's death. It was diagnosed as obsessive compulsive disorder and treated with fluoxetine $40 \mathrm{mg}$ and trauma focused psychotherapy, grief therapy for hypertrophied grief and anger management for the anger towards the ex-wife for having taken a huge alimony.

\section{Case 3 (Life threatening event, fear of humiliation)}

Mr. C aged 19 years presented with complaints of repeated washing hands, washing his clothes, washing currency notes from 1 month. He had discontinued going to college because he was indulging in long hours of cleaning rituals. Upon further inquiry he narrated an event that occurred in his college several months ago. He was challenged by a group of his friends to go to the bottom of a tube well that was dry and get a handful of sand from the bottom of the well. Patient was afraid as he got in to the well that was filthy, full of excreta, stench and also deeper than he had estimated. Finally he managed to get a handful of that filth from the well, subsequently patient began to feel dirty was constantly washing his hands, washing his clothes and also washing currency notes (Since if he lost the bet/challenge he had to pay the money in currency notes of 500 rupees). Patient was diagnosed with obsessive compulsive disorder, treated with Clomipramine $75 \mathrm{mg}$ and Cognitive Behavior Therapy for fears of contamination and hand washing compulsions.

\section{Case 4 (Domestic violence)}

A middle aged woman Mrs. C employed as a manager in a multinational company was referred for evaluation and treatment following a suicidal attempt with 30 tablets of nitrazepam. Patient reported history of two divorces following marriages that were physically abusive (domestic violence) and emotionally abuse. She had moved from her second husband about 12 months ago. She had two significant life events that occurred a few years prior to the onset of symptoms: Mother and sister had both died in rapid succession of each other of Carcinoma. Mrs. C reported repeated checking of her door locks, and sleeping with a knife under her pillow for the past 2-3 months. The checking was considered by her to be unnecessary and was excessive and would lead to a delay in sleeping by a few hours every night. She reported that she was fearful of sleeping alone although the fear was not held with a delusional intensity. She did not have other persecutory or referential delusions. She did not report perceptual disturbances. She was prescribed Fluoxitene along with a combination of Cognitive Behavior Therapy and supportive therapy due to the ongoing stressors in her life.

\section{Case 5 (Adoption viewed as rejection by biological parents, trauma of sudden death of adoptive father)}

A single unmarried unemployed woman Ms. D in her early thirties presented with 3 months duration of symptoms of unwanted sexual and obscene thoughts towards her dead adoptive father who had died about 12 months ago. She also had intrusive and repeated irrational fears of fatal illness befalling her adoptive mother, compulsive checking with the mother for possible symptoms of various fatal illnesses, compulsive reassurance seeking from mother and relatives about her health \& safety. Patient was adopted as a baby from a family that was related to her adoptive father. The family had four daughters, and patient was the fourth daughter conceived due to failure of family planning, although her biological family was well to do, because of the gender and birth order the girl was given away in adoption. Family had strong reservations about abortion and hence gave away the new born in adoption. Patient nursed anger, sense of rejection towards her biological father, though was sympathetic to her biological mother as she saw her as a victim of oppressive patriarchy. Patient perceived her adoption as a traumatic start of her life. She was strongly attached to her adoptive father, hence felt traumatized by his death due to sudden cardiac illness. Ms. D was treated with Fluvoxamine and there was an integration with psychotherapy that focused on grief and loss.

\section{Case 6 (Intrusive inquiry about suicide)}

Miss. $\mathrm{K}$ aged 15 years had received a prescription of Zolpidem $10 \mathrm{mg}$ due to exam anxiety causing insomnia and had consumed 10 tablets of the drug as she suffe- 
red from immediate memory loss after consuming one tablet and consumed the others in a state of cognitive impairment. However she was admitted to Intensive Care Unit and was asked about the possible suicidal intention when she consumed the tablets. Patient felt traumatized by the admission and the interrogation, subsequently developed obsessive fears of committing suicide, refusal to be alone, compulsively removing the objects that can be used to self harm from the house. Patient was treated with Cognitive Behavior therapy for obsessive compulsive disorder.

\section{Case 7 (Dog bite)}

Mr. L a 25-years-old man presented with compulsive checking of his face in the mirror to reduce the obsessive fear of seeing the face of a dog in the mirror and also a fear of rabies. This was perceived by him as senseless and excessive. He would spend several hours checking his face at the expense of other daily activities. These symptoms developed several months after the patient was bitten on the face by his pet dog, the dog did not leave him and he needed to be rescued, his wounds had to be stitched. Patient did take anti-rabies vaccine. He was advised by villagers and family that when he looks at a mirror if he did not see the face of a dog he would not be affected by Rabies. He was diagnosed with OCD and treated with sertraline and psychotherapy for his magical thinking consisting of thought action fusion.

\section{Case 8 (Domestic violence)}

Mrs. S a 35-year-old woman presented with obsessive fears of end of the world on 12.12.2012, Patient had more fears of death of in laws and husband than death of herself. Patient feared watching TV or reading any news about the dread of the date. The fears were perceived by her to be excessive and intrusive and unnecessary. These fears were not held with a delusional conviction. For several years she had suffered serious harassment by in laws who had physically assaulted and cursed her to die. Patient was diagnosed with obsessive compulsive disorder and treated with anti-obsessive drugs and Cognitive Behavior Therapy.

\section{Case 9 (Sexual harassment)}

A middle aged woman Mrs. $\mathrm{H}$ working as a clerk in a government agency presented with a 2-3 month onset of fears of making eye contact with colleagues as she feared that she has looked at inappropriate aspects of their anatomy and they may have come to know this. This was recurrent and intrusive and patient was clinically depressed due to this complaint. Patient had been sexually harassed by one of the colleagues and she had complained about it. The sexual harassment had commenced about a year ago and continued for a few months. Patient had experienced the entire incident as very traumatic and was angry with many people who had supported the harasser. Recently the colleague had left the office. Patient was diagnosed with Obsessive com- pulsive disorder and treated with Fluoxitene. Supportive psychotherapy was integrated to the pharmacological treatment during subsequent sessions.

\section{Case 10 (Diagnosis of mental illness and consequent behavior due to the illness is the trauma)}

Mr. K aged 32 presented with repeated recurrent intrusive fears of relapse of mania whenever he felt happy or was communicating freely with his friends or family or felt attracted to a woman for the past few months. This was excessive and intrusive and resulted in anxiety and difficulty with concentration. This fear was not accompanied by depressive symptoms. Patient had been diagnosed with bipolar affective disorder few years ago and was on prophylactic dosage of mood stabilizers to prevent the relapse. But patient was so embarrassed by the last episode that caused a social disruption, and felt traumatized by the diagnosis, subsequently patient developed irrational fears towards any feeling of happiness or sociability. Because of the risk of drug induced mania, patient was treated only with Cognitive Behavior Therapy for Obsessive Compulsive Disorder.

\section{Case 11 (Accidental death of husband witnessed)}

Mrs. N a 64-years-old lady presented with repeated intrusive questioning about the safety of grand children in the evenings if they have gone to tuitions, repeated interference and stopping of grown up sons and daughters from attending social gatherings or parties in the houses of the friends. On further enquiry patient and her husband had gone to attend the house warming party of a family friend. And the upper floor of the building was under construction and patient's husband lost his balance and fell from the second floor and died. Patient suffered from normal grief according to the relatives and was not treated medically for the same; though the accidental death was witnessed by the patient, who had nightmares, avoided staircases in the house in the first few months after the death. However patient started complaining about the safety and repeated checking of house locks since 1 year. Patient was treated with anti-obsessive medication for the same.

\section{Case 12 (Death of son by murder)}

Mrs. M an 85-years-old lady presented with complaints of inhaling nail polish remover leading to several blood dyscrasias and compulsion to gift expensive jewels, watches to acquaintances and friends. She revealed that her 30-year's-old unmarried son was murdered 30 years ago. The police were unable to find the murderers, suspected it to be a mugging incident that had caused murder. Her son had worn expensive gold chain, ring and watch that were stolen; the finger wearing the ring was cut off from the hand. She was diagnosed with obsessive compulsive disorder predominantly compulsions along with an Inhalant abuse and was treated with Cognitive Behavior therapy and insight oriented psychotherapy. 
Case 13 (Father with motor neuron disease on ventilator, death of grandmother to hepatic carcinoma)

A young girl Miss. A presented with fear of eating a full meal, rituals to prevent harm to her father suffering from motor neuron disease and bed bound, chanting prayers in a particular sequence, repeating the prayer repeatedly if the order was lost, fear of stepping on insects in the pavements hence reluctant to walk on the roads in rainy season. Patient revealed that her grandmother died of Hepatic - Carcinoma on a day when patient had gone out to eat with friends and later felt guilty over it, as her grandmother was unable to eat any food for several months prior to that. Later felt if she ate well "Something bad would happen". Her father was from Jain community and they had strong principles of "Ahimsa" and not killing any living being. She practiced his religion; mother and other family members did not follow it strictly. Patient was started on fluvoxamine and cognitive behavior therapy. Patient had achieved near total symptomatic relief with therapy and fluvoxamine $100 \mathrm{mg}$ in 3 months.

\section{Case 14 (Investigation without informed consent as assault)}

Mr. J 32-year-old man presented with a fear that something was altered in his genitals and a constant obsessive doubt that his food did not smell like it always did and it did not taste the same, Patient had noticed blood in his urine 6 months ago and consulted a urologist for the same. He underwent an urethrogram without allegedly due consent process. He felt violated and a doubt emerged whether he had a stricture. He consulted another surgeon whose opinion was inconclusive. He did not undergo any further procedures. Subsequently he had intrusive thoughts of permanent harm caused by the urethrogram, and a recurrent doubt that his food did not smell the same, nor taste the same. He would repeatedly collect his urine sample and repeatedly check with friends and family whether food tasted alright or not. He was started on Fluvoxamine and trauma focused psychotherapy. Patient achieved complete remission of doubts and checking with in 8 weeks.

\section{Case 15 (Multiple surgeries for life threatening he- alth complaints)}

A lady Mrs. V aged about 54 years presented with complaints of an obsessive fear that there were no organs in her abdomen and to fill that sense of emptiness, she would compulsively eat and had morbid obesity. On further enquiry it was reported that patient had undergone surgeries such as cholecystectomy for gall stones, appendicectomy for appendicitis, and hysterectomy for fibroids in the last 2 years. The series of intra-abdominal surgeries conducted within short intervals of time traumatized the patient. Patient was diagnosed with obsessive compulsive disorder and treated with cognitive behavior therapy and Fluoxitene. Patient achieved near total relief of symptoms within 12 weeks of psychotherapy and pharmacotherapy.

\section{Case 16 (Narration of past romantic relationship by fiancé)}

Mr. Q aged 30 years reported to the psychiatrist with obsessive fears that his fiancé may cheat him in the future, hence was avoidant of marrying her. He said that after the engagement his fiancé had confided in him about a past romantic relationship that had ended. Patient subsequently traced her Facebook links and discovered that she had gone to an excursion with her ex-boyfriend. Subsequently he had repeated intrusive thoughts of his fiancé cheating on him after marriage. Though he recognized this to be irrational, he was unable to stop these thoughts. He was treated only with cognitive behavior therapy and experienced significant relief of symptoms.

\section{Case 17 (Sexual assault by transgender)}

Mr. R aged 24 years reported repeated intrusive thoughts that he may become a transgender. He also had a history of multiple substance abuse: cannabis and alcohol. About 6-9 months ago he was rejected by a girl with whom he was in love due to his short stature. He then developed low self esteem, ideas of worthlessness, helplessness and hopelessness and a depressed mood. His friend took him to a brothel to help with his mood. While he was intoxicated with cannabis he had sexual intercourse with a transgender. According to patient he felt forced and surprised by the encounter, he was also deeply disgusted. Subsequently after few days, he started to feel extremely anxious by the thought that he may also become a transgender. Though he initially felt it was irrational, later he was very anxious, suffered from insomnia. A diagnosis of Major Depression and obsessive compulsive disorder was made and was commenced on sertraline and cognitive behavior therapy. There was a gradual improvement in mood over the next few weeks and a subsequently there was a reduction in the intrusive thoughts of becoming a transgender.

\section{Case 18 (Gaming as compulsion)}

Mr. S an adolescent aged 17 years was brought by his uncle with complaints of academic decline and compulsive playing of games in the mobile. They were not interactive games and there was no internet connection to the mobile. On further enquiry, patient had lost his father to hepatic carcinoma when he was in year 7 at school. Mother died of a sudden gruesome accident when he was in year 9. His mother was the owner of a garment factory, there was a power failure and she had entered a loom machine to pick up an article and the power returned, so she was strangled to death as the loom churned her like a fiber of cloth. Patient had seen her dead body after the accident. He appeared for the year 10 exams and did well. Over the next two years there was a decline in academic standards, compulsive 
video gaming as a measure to block out intrusive obsessional images of the dead body of his mother. However he merely passed his $12^{\text {th }}$ standard because of excessive playing with the downloaded mobile games. Patient reported that he was repeatedly seeing the image of his mother's dead body and was compulsively playing games to erase that image in his mind. Patient was treated with sertraline and grief therapy for complicated grief with a gradual improvement of the intrusive image and reduction in time spent in playing video games.

\section{Case 19 (Death of husband by suicide)}

Mrs. $X$ aged 43 years presented for the first time with repetitive urges to lock the door, and irrational recurrent fears of something terrible that would happen in her house for 2 months. Patient had stopped working as a result. She was a single parent of an 18-years-old daughter and was a victim of domestic violence 20 years ago. Her husband was diagnosed with depression, suspected her of infidelity and later committed suicide. Patient was able to complete her studies of law, procure a job as a lawyer but lived isolated from family and friends. Patient had avoided all reminders of the grief and never spoken about it to the daughter also. Patient responded to fluvoxamine and also underwent grief therapy. The grief therapy brought out anger towards the deceased husband who had hung himself to death. Patient came successively for two years experiencing similar symptoms during anniversaries.

\section{Discussion}

All these cases had initially presented with Obsessive or Compulsive symptoms that met the full criteria for OCD as per ICD-10 classificatory system [1]. OCD was diagnosed as a single condition. During assessment there was a common occurrence of past traumatic events of various hues among a diverse population of patients representative of an Indian subpopulation. The high scores on Y-BOCS scale, and experiences of traumatic life events as per life events check list provide validation to these clinical observations. All patients responded to trauma focused psychotherapy and pharmacotherapy. This is similar to the findings by Shavitt and others [5]. The findings from this non-western (Indian) population that traumatic events are significantly represented among patients is similar to a recent cross cultural study among a Brazilian population [7]. All the above mentioned cases had delayed expression of symptoms after 6 months of the event. Also at the outset, it is important to acknowledge that this case series collected as a part of semi-structured clinical assessments have their own limitations in the absence of multi-modal structured assessments.

It can be noted that cases $2,4,5,11,12,13,18,19$ were caused by sudden death of a loved one. In this series a substantial proportion of patients had a traumatic event of a sudden unexpected death of a loved one. Death of a loved one is the most frequent cause of PTSD accounting for one third of all cases [10]. Within this group, a smaller subgroup of patients cases 11,12 , 18 and 19 witnessed violent deaths by unnatural causes and additionally experienced complicated grief and PTSD along with OCD, which is similar to previous studies [11].

Rape or sexual assault is almost always associated with post traumatic stress disorder, hence a term called Rape trauma syndrome [12]. Cases 9 and 17 indicate such a trauma. In case 17 , where the patient was made to perform sodomy on a transgender commercial sex worker while he was inebriated can be defined as rape. It can be argued that such a trauma lead to obsessional doubts about his own sexual identity. In case 9, continuous sexual harassment at work place eventually lead to a delayed form of OCD and illustrates the issues raised of gender inequalities at work place and victim blame and sexism [13,14]. Case 14 and case 15 are post traumatic stress disorders experienced after diagnosis of life threatening illness and treatment [15]. It is important to note that patient was psychologically healthy and stable for a reasonable length of time after the treatment, obsessive compulsive symptoms started after a time interval in which patients had seemingly forgotten about the fear or the impact of the traumatic event. This illustrates an important clinical point that trauma may be forgotten by the patient at the time of presentation with a different set of symptoms viz., obsessions and compulsions [16]. Obsessions of feeling as if her abdomen (case 15) was devoid of all organs and in case 14 of the patient feeling that his urinary tract was defective were highly suggestive of isolation of affect, reaction formation, classical psychodynamic neurotic defenses employed in obsessive compulsive disorder.

Many of the cases illustrate that careful determination of the type of trauma rather than documenting of an occurrence of a generic negative life event may shed light on the phenomenology of subsequent OCD symptoms and allow sophisticated psychological understanding of the origins of the OCD symptoms. This has the potential to inform the treating psychiatrist or therapist to explore and challenge the OCD symptoms through CBT approaches along with conventional pharmacological treatments.

\section{Conclusion}

This case series suggests that exploring trauma that occurred months earlier to the presentation of $O C D$ may provide an aetiological substrate to the occurrence of OCD and may inform clinical approaches that are broader than conventional medication treatments for OCD. This case series of a diverse and predominantly help seeking non-western population adds an important perspective to the developing construct of delayed type post traumatic OCD. 


\section{Declaration of Interest}

None.

\section{References}

1. World Health Organization (1992) The ICD-10 classification of mental and behavioural disorders: Clinical descriptions and diagnostic guidelines. Geneva: World Health Organization.

2. De Silva P, Marks M (2001) Traumatic experiences, post-traumatic stress disorder and obsessive-compulsive disorder. Int Rev Psychiatry 13: 172-180.

3. O'Connor J, Fell M, Fuller R (2010) Escaping, forgetting and revisiting the scene: The post-traumatic compulsion to repeat in obsessive-compulsive disorder. Couns Psychol Q 23: $55-66$.

4. Borg MC, Braga DT, Lêgo S, D'Alcante CC, Sidrim I, et al. (2011) Cognitive dysfunction in post-traumatic obsessive-compulsive disorder. Aust N Z J Psychiatry 45: 76-85.

5. Shavitt RG, Valerio C, Fossaluza V, da Sila EM, Cordeiro $Q$, et al. (2010) The impact of trauma and post-traumatic stress disorder on the treatment response of patients with obsessive-compulsive disorder. Eur Arch Psychiatry Clin Neurosci 260: 91-99.

6. Fontenelle LF, Cocchi L, Harrison BJ, Shavitt RG, do Rosario MC, et al. (2012) Towards a post-traumatic subtype of obsessive-compulsive disorder. J Anxiety Disord 26: 377-383.

7. Mederiros GC, Torres AR, Boisseau CL, Leppink EW, Eisen JL, et al. (2017) A cross cultural clinical comparison between subjects with obsessive-compulsive disorder from the United States and Brazil. Psychiatry Res 254: 104-111.
8. Goodman WK, Price LH, Rasmussen SA, Mazure C, Delgado $P$, et al. (1989) The Yale-Brown obsessive compulsive scale: II validity. Arch Gen Psychiatry 46: 1012-1016.

9. Gray M, Litz B, Hsu J, Lombardo TW (2004) Psychometric properties of the life events checklist. Assessment 11: 330341.

10. Breslau N, Kessler R, Chilcoat HD, Schultz LR, Davis GC, et al. (1998) Trauma and Post traumatic stress disorder in the community: The 1996 Detroit Area Survey of Trauma. Arch Gen Psychiatry 55: 626-632.

11. Hargrave PA, Leathem JM, Long NR (2012) Peritraumatic distress: It's relationship to posttraumatic stress and complicated grief symptoms in sudden death survivors. J Trauma Stress 25: 344-347.

12. Burgess AW, Holmstrom LL (1974) Rape trauma syndrome. Am J Psychiatry 131: 981-986.

13. Pedersen SH, Strömwall LA (2013) Victim blame, sexism and just-world beliefs: A cross-cultural comparison. Psychiatr Psychol Law 20: 932-941.

14. Stamarski CS, Son Hing LS (2015) Gender inequalities in the workplace: The effects of organizational structures, processes, practices, and decision makers' sexism. Front Psychol 6: 1400.

15. Edmondson D (2014) An enduring somatic threat model of posttraumatic stress disorder due to acute life-threatening medical events. Soc Personal Psychol Compass 8: 118-134.

16. Van der Kolk BA, Fisler R (1995) Dissociation and the fragmentary nature of traumatic memories: Overview and exploratory study. J Trauma Stress 8: 505-525. 